\title{
XI International Symposium on Photon Echo and Coherent Spectroscopy (PECS - 2017): preface
}

\author{
K.R. Karimullin ${ }^{1,2}$, A.A. Kalachev ${ }^{3}$, A.V. Naumov ${ }^{1,2}$, S.V. Sazonov ${ }^{4}$, and V.V. Samartsev ${ }^{3}$ \\ ${ }^{1}$ Institute for Spectroscopy RAS, 108840 Moscow, Troitsk, Russia \\ ${ }^{2}$ Moscow State Pedagogical University, 119991 Moscow, Russia \\ ${ }^{3}$ E. K. Zavoisky Physical-Technical Institute, Kazan Sci. Center RAS, 420029 Kazan, Russia \\ ${ }^{4}$ National Research Center "Kurchatov Institute", 123182 Moscow, Russia
}

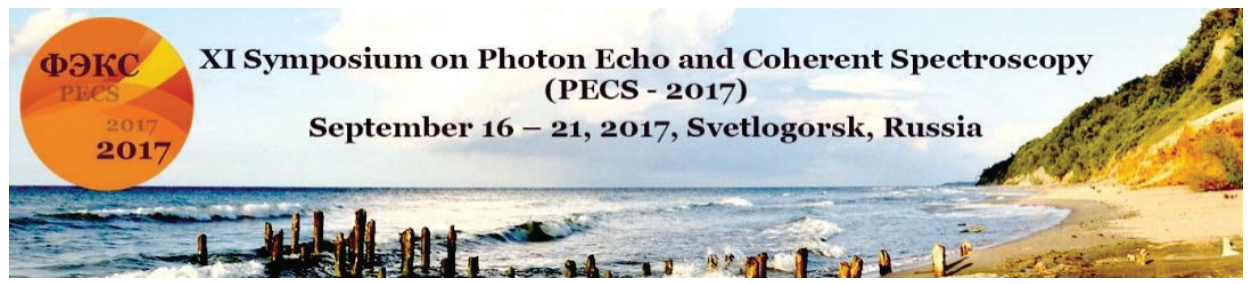

The International Symposium on Photon Echo and Coherent Spectroscopy (PECS) is a regular quadrennial scientific meeting. Symposium originates in Kazan at the PhysicalTechnical Institute of the Kazan Branch of the USSR Academy of Sciences (now the E. K. Zavoisky Physical-Technical Institute), where in 1963 the phenomenon of the photon echo was theoretically predicted. The first PECS was held in 1973 as All-Union Conference shortly after the first in the USSR experiments on the photon echo in a ruby crystal. The second symposium was also held in Kazan in 1981. Later the Symposium was organized every four years: 1985 - Kharkov (Ukraine, USSR), 1989 - Kuibyshev (now Samara), 1993 - Volga-Laser-Tour'93, 1997 - Yoshkar-Ola, 2001 - Novgorod the Great, 2005 Svetlogorsk, 2009 - Kazan, 2013 - Yoshkar-Ola.

PECS-2017 was organized in Svetlogorsk (Kaliningrad region, Russia) from $16^{\text {th }}$ till $21^{\text {th }}$ September 2017 by the E. K. Zavoisky Physical-Technical Institute (Kazan, Russia, www.kfti.knc.ru/eng) and the Institute for Spectroscopy of the Russian Academy of Sciences (Moscow-Troitsk, Russia, www.isan.troitsk.ru/en) on the base of the company "Center for Energy Efficiency" (Kaliningrad, Russia, http://www.cef39.com/en).

The PECS program covered such topics as photon echo and coherent transients, nonlinear interaction of radiation with matter, optical memory and information processing, spectroscopy of ultrafast processes, quantum optics and quantum technologies, atomic optics and nanooptics, spectroscopy and microscopy of single quantum emitters. Scientific program of PECS-2017 included 13 plenary lectures and 18 invited talks, 42 oral talks, 31 poster talks, authored in total by more than 200 scientists from 14 countries (Russia, Belarus, Ukraine, Great Britain, Italy, Germany, France, The Netherlands, Poland, Portugal, Romania, India, USA, and Republic of South Africa).

Within the framework of the Symposium, a competition for young scientists was held. The winner of the competition has received a recommendation from the Organizing 
Committee to participate in the competition for Fresnel Prize for the Young Scientists from Quantum Electronics and Optics Division of the European Physical Society.

This issue of the EPJ Web of Conferences consists of the expanded version of abstracts of the selected talks presented at the Symposium. The issue is recommended for specialists who work in the field of nonlinear and coherent optics and spectroscopy, as well as for M.S. and Ph.D. students. The full program and details about the Symposium can be found on the web-site www.pecs.su). The next $12^{\text {th }}$ International Symposium on Photon Echo and Coherent Spectroscopy will be organized by the E. K. Zavoisky Physical-Technical Institute and the Institute for Spectroscopy of the Russian Academy of Sciences in 2021.

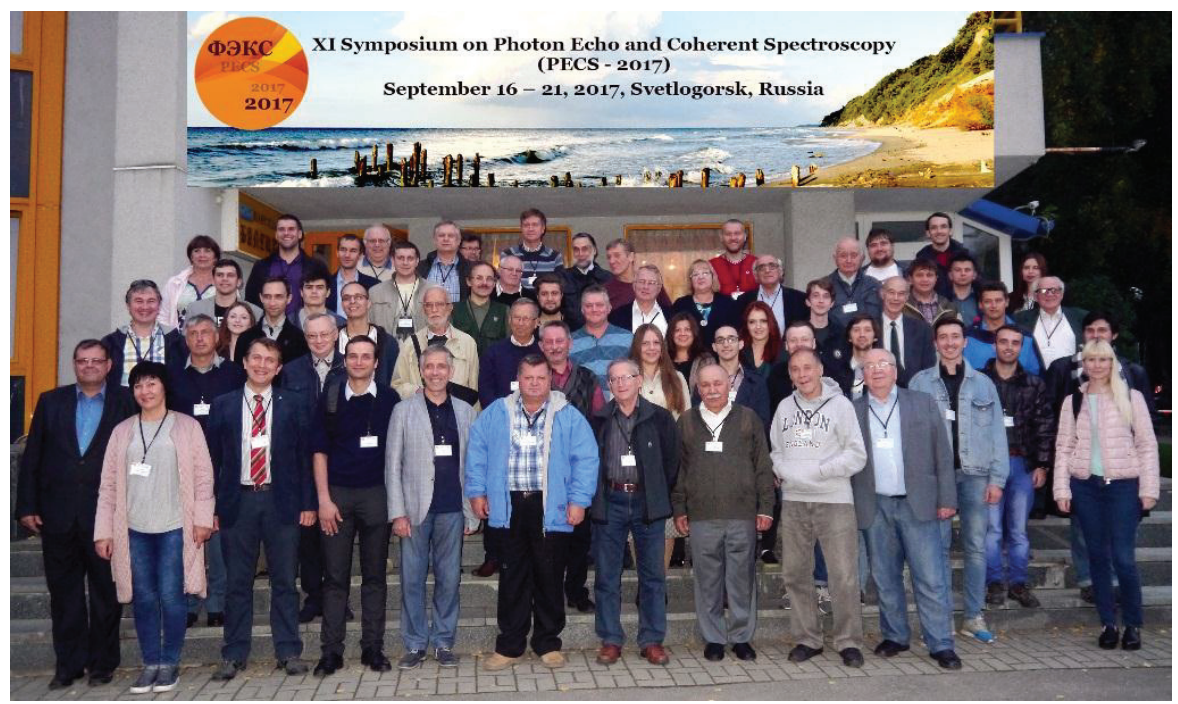

Participants of the Symposium

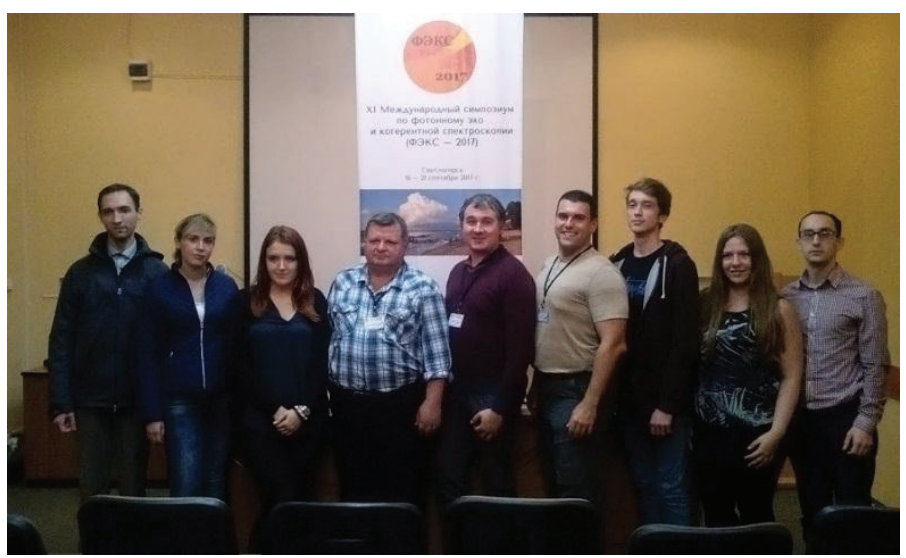

Organizing committee of PECS-2017

The financial support is acknowledged from the Federal Agency for Scientific Organisations of Russia and from Russian Foundation of Basic Researches (project No 17-02-20495). Members of local Organizing Committee of PECS - 2017 are involved in leading scientific school of Russia NSh7035.2016.2 "Spectroscopy of atoms, molecules and condensed matter". 